NASA Contractor Report 182224

\title{
A Preliminary Design Study of Supersonic Through-Flow Fan Inlets
}

Paul J. Barnhart

Sverdrup Technology, Inc.

NASA Lewis Research Center Group

Cleveland, Ohio

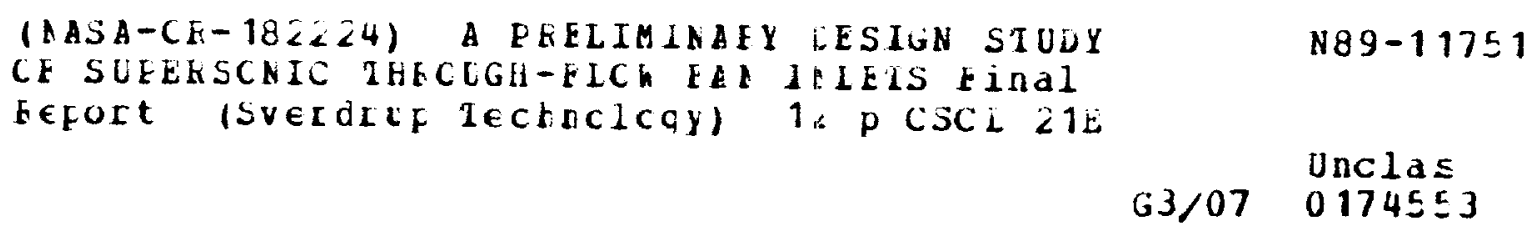

November 1988

Prepared for

Lewis Research Center

Under Contract NAS3-24105

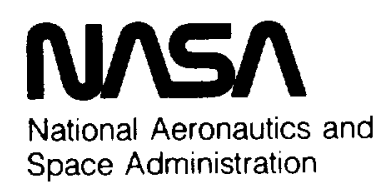



A PRELIMINARY DESIGN STUDY OF SUPERSONIC

THROUGH-FLOW FAN INLETS

\section{ORIGINAL PAGE IS OF POOR QUALITY}

Paul J. Barrhart*

Sverdrup Technc logy. Inc.

NASA Lewis Researc:1 Center Group

Cleveland, Or io 44135

\section{ABSTRACT}

For Mach 3.20 cruise propulsion systems, preliminary design studies for two supersonic through-flow fan primary inlets and a single core inlet were undertaken. Method of characteristics and one-dimensional performance techniques were applied to assess the potential improvements supersonic through-flow fan technology has over more conventional systems. A fixed geometry supersonic through-flow fan primary inlet was found to have better performance than a conventional inlet design on the basis of total pressure recovery, air flow, aerodynamic drags and size and weight.

\section{NOMENCLATURE}

$\begin{array}{ll}\text { A } & \text { area } \\ \text { BPR } & \text { bypass ratio } \\ C_{D} & \text { drag coefficient } \\ \text { M } & \text { Mach number } \\ \text { PT } & \text { total pressure } \\ \text { R } & \text { radial distance } \\ \text { VC } & \text { normalized fan corrected speed } \\ X & \text { axial distance }\end{array}$

\section{Subscripts}

$\begin{array}{ll}0 & \text { free stream conditions } \\ 1 & \text { upstream conditions } \\ 2 & \text { downstream conditions } \\ \text { C } & \text { cowl lip location } \\ \text { ff } & \text { fan face conditions } \\ \text { pre } & \text { preentry spillage }\end{array}$

\section{INTRODUCTION}

In pursuing the technologies required for efficient long range supersonic cruise aircraft, NASA has sponsored a number of studies to identify suitable propulsion system concepts. In the past, conventional and variable cycle engines were considered the most likely candidates for supersonic cruise applications. With renewed interest in civilian supersonic cruise flight in the Mach 2 to 5 speed range, another engine design has shown the potential for higher efficiency propulsion than more conventional proposals. The supersonic through-flow fan engine has been analyzed in other studies $1-3$ and indications are that this concept promises significant reductions in specific fuel

*Research Engineer, Member AIAA consumption. One possible configuration of this engine shown in Figure 1 , incorporates a single stage supersonic through-flow fan. This turbomachinery element operates with supersonic axial Mach numbers both at the fan face and stator exits.

The engine design in Figure 1 has components arranged similar to a conventional turbofan inlet delivers axisymetric primary fan face. Behind the stator exit is a core inlet which bypasses some of the fan exit flow and diffuses the remaining air to subsonic speeds, entering a high pressure core spool. The fan spool is powered by a second turbine following the core spool. Finally, the core air flow is discharged through a nozzle. An attractive feature of the supersonic through-flow fan engine is the short all supersonic inlet, resulting in lower weight and lower inlet drags. The single stage fan features lower weight and cost, as well as more rugged blading. Another desirable aspect of the engine cycle is that the bypass ratio decreases with increasing flight Mach number, providing higher cruise thrust.

Reference 3 shows that much of the improved specific fuel consumption for supersonic through-flow fan engines results from potential improvements in inlet efficiencies for long range supersonic cruise applications. This study addresses the design and performance characteristics of the inlet systems for supersonic through-flow fan propulsion concepts. Two different types of primary inlet designs, a variable geometry and a fixed geometry inlet, as well as a single core inlet design are examined in this study. Additionally, the supersonic through-flow fan inlets are compared with a conventional inlet on the basis of performance and weight. All the inlets studied have the same design Mach number of 3.20 and are axisymmetric configurations.

\section{METHOD OE ANALYSIS}

The sequence of analyses used in this study was to first define the inlet system geometry, second assess the internal supersonic flow field, and finally predict the inlet performance in terms of air flow, pressure recovery, and aerodynamic 
drags. In defining the inlet geometry, parameters such as centerbody angle, cowl iip angle, fan face hub/tip ratio, and any control schemes had to be determined. The method of characteristics inlet design code in reference 4 was used in defining some of the inlet geometry where appropriate.

For the assessment of the supersonic internal inlet flow field, another method of characteristics inlet analysis code described in reference 5 was utilized. The actual program was modified to suit the particular interests of this preliminary design study. The design and analysis process was not a simple sequential operation, but rather a series of iterations on various designs were performed in conjunction with the performance analyses.

The overall inlet performance characteristics were calculated by onedimensional analytic techniques assembled from references 6-11. These onedimensional analyses were incorporated into a computer program which could rapidly compute the inlet performance characteristics from takeoff to cruise. However, the inputs to this inlet performance code are the basic inlet geometry, and therefore the method of characteristics design and analysis procedure had to be completed first. The inlet performance elements modeled were: air flow, total pressure recovery, and aerodynamic drags including preentry spillage, cowl lip, cowl wave, bleed, and bypass. The total pressure recovery calculation factored in the losses associated with: shock waves, external friction, sharp lip, subsonic diffuser, and internal friction.

For the primary supersonic throughflow fan inlets the objectives of the preliminary design were first to provide as uniform a Mach number distribution across the fan face as possible. A second goal was maximizing the total pressure recovery at the fan face. other design objectives were low inlet drags and high air flow capacity, in addition to low inlet weight. For the core inlet the design objective was to provide a bypass ratio variation with flight Mach number and fan speed that would satisfy a balanced engine cycle. It was also desired to find a design and control scheme which would perform well over the supersonic through-flow flight regime. Again, size and weight of the core inlet were desired to be kept as low as possible without undo sacrifice in total pressure recovery.

Two possible schemes for operation of supersonic through-flow fans have been identified ${ }^{3}$ which require different primary inlet concepts. The first supersonic through-flow fan type assumes that the fan face Mach number is supersonic on the runway. The inlet is expected to provide the desired operating fan face Mach number through a variable geometry control scheme. This is envisioned to be an adjustable area inlet throat which is choked at takeofe and varied to provide the fan with the required incoming Mach number for efficient operation over the flight envelope. The second concept assumes that the supersonic through-flow fan is capable of operation with subsonic inflow as well. In this scheme, the fan face Mach number is subsonic from takeoff to low supersonic speeds. The fan then transitions to supersonic through-flow mode in flight and both the inlet and fan start simultaneously. Since the fan is capable of operation over a wide range of fan face Mach numbers and is expected to be able to transition from subsonic to supersonic through-flow operation in flight, a very simple fixed geometry inlet may satisfy for this operating scheme.

The preliminary designs of two primary inlets for these distinct fan operation schemes are presented in this study. A single core inlet capable of operation with both supersonic throughfiow fan schemes is also presented. Finally, the design and performance of a conventional inlet for the same cruise Mach number is provided for use as a comparison tool in assessing the inlet system improvements possible with supersonic through-flow technology.

\section{RESULTS AND DISCUSSION}

\section{Variable Geometry Primary Inlet}

As previously mentioned, one supersonic through-flow fan operation concept requires the fan face Mach number always be supersonic and set by and controlled by a variable geometry inlet. The preliminary design chosen for this concept is shown in Figure 2. The method of characteristics solution net is superimposed on the outline of the inlet geometry. The centerbody is a simple conic section of 12.5 degrees half angle. The cowl lip is located such that the conical shock wave intersects at the design Mach number of 3.20 , as shown. The initial internal cowl lip angle is 0.0 degrees, and the internal cowl lip shock wave is cancelled on the centerbody intersection. The remainder of the internal flow is turned isentropically through a shallow s-shaped annulus up to the fan face. The fan face hub-to-tip ratio is 0.66 , chosen such that the fan face Mach number should be 2.40 at the inlet design Mach number of 3.20 . The variable geometry requirement is satisfied for this inlet by translating the centerbody whereby the minimum flow area can be set within limits by forward and rearward translation.

The inlet operation and control 
proceeds as follows. At takeoff the centerbody is positioned so as to provide the desired fan face Mach number by fixing the throat area. By choking the throat, the flow can be accelerated to a desired supersonic Mach number. The fan face Mach number is thus set by the ratio of the choked throat area to the fan face area. For this design, the permissible fan face Mach number variation by choking the inlet throat is from 1.30 to 1.90 . The inlet can be operated in this manner from takeoff to a flight Mach number of 1.70 . When the free stream Mach number is supersonic a normal shock is formed ahead of the cowl lip, and the unstarted inlet subsonic flow is accelerated up to Mach I. 0 at the throat and then supersonic to the fan face. At Mach 1.70 , the inlet can transition to started operation with supersonic flow from free stream through the throat up to the fan face. Above free stream Mach numbers of 1.70 the fan face Mach number is determined not by a choked throat area (since the throat is now supersonic) but by the amount of supersonic forebody spillage as set by the centerbody translation.

The fan face Mach number profiles as determined by method of characteristics analyses is given in Figure 3 over the free stream Mach number range 1.70 to 3.20. From Mach 3.20 to 2.00 the centerbody was translated to match the cowl lip shock wave centerbody cancellation point in order to minimize the reflected shock train system. This technique was effective at the design point where the fan face Mach number distribution is nearly flat, but was less successful off design. The existence of shock waves can be seen in the profiles at Mach numbers 2.80 to 2.00 . From free stream Mach numbers of 2.00 to 1.70 the centerbody was further extended to set the average fan face Mach number at approximately 1.50 .

Figure 4 shows the average fan face Mach number for the inlet started operation, free stream Mach numbers above 1.70, and a series of fixed fan face Mach number operating $l$ ines in the inlet subsonic and unstarted mode. This figure represents the permissible supersonic through-flow fan operating range over the flight Mach number extent. For a centerbody translation schedule fixed as a function of started free stream Mach number, the single curve will dictate the fan face Mach number and is thus invariant. For unstarted operation the fan face Mach number can be set anywhere within the limits of 1.30 to 1.90 by adjustment of the choked throat area.

Figures $5-7$ show the impact of fan face Mach number operation on the inlet air flow, total pressure recovery, and inlet drag schedules. The inlet air flow, in Figure 5 , is represented by the ratio of the free stream cross-sectional flow area to the cowl lip area. For inlet tarted operation, the amount of air captured by the inlet at a given flight peed, and hence passed through the fan, is fixed and shown as the single operating ine above Mach 1.70. Since the inlet -low to the fan face is supersonic, air robably cannot be effectively bypassed efore the fan, and therefore the fan must iccept all the air flow supplied by the inlet. In the unstarted operation mode the amount of air supplied can be varied गy setting different fan face Mach numbers is shown in the series of curves below Yach 1.70 .

Figure 6 shows the total pressure recovery over the flight Mach number zange. At the design frees stream Mach number of 3.20 the recovery is 0.96 . The characteristic drop in recovery is seen before the inlet starting free stream Mach jumber of 1.70 . The sharp lip losses dominate the recovery curves below Mach 0.60 with the highest fan face Mach number oroviding the best takeaff pressure recovery. Figure 7 shows the inlet preentry spillage drag coefficients. Very noticeable is the impact on drag coefficient by fan face Mach number. An 8 fold increase is seen between fan face Mach numbers of 1.30 and 1.90 at a free stream Mach number of 1.70 . Therefore, to avoid prohibitive inlet drags when in unstarted operation, the fan face Mach number should be set as low as possible. This provides the largest throat area and thus highest air flow, resulting in the smallest preentry spillage drag.

The performance calculations for this preliminary design of a variable geometry primary inlet do not include takeoff doors or a bypass system, since both are not applicable to inlets systems of this type. Additionally, the argument is put forth that this inlet should not require any boundary layer bleed either, owing to the relatively small amount of diffusion performed and the lack of a terminal normal shock system requiring stabilization. Therefore the preentry spillage and cowl wave drags represent the only contributing aerodynamic drags for this type of inlet, nacelle skin friction being neglected in this analysis. The cowl wave drag coefficient for a 3.0 deqree external slope is 0.007 at a free stream Mach number of 3.20 .

\section{Fixed Geometry primary Inlet}

The other concept for operation of a supersonic through-flow fan is a dual mode scheme with both subsonic and supersonic inflow capabilities. A fixed geometry primary inlet for use with such a fan is shown in Figure 8 . This inlet also has a 12.5 degree half angle conic centerbody designed for shock on 1 ip at a free stream Mach number of 3.20 . The centerbody contour blends from the initial 12.5 deqrees gradually to 7.0 degrees. The internal cowl lip angle is initially 3.0 degrees, blending to 0.0 degrees ahead of 
the fan face. At the intersection of the internal cowl lip shock wave, just ahead of the fan face, is a shock cancellation on the centerbody resulting in a fan face hub slope of 3.0 degrees. The hub-to-tip ratio at the fan face was chosen to be 0.60 for this preliminary design. This fixed geometry primary inlet self starts at a free stream Mach number of 1.60 .

The fan face Mach number profiles for the inlet started operation as calculated by method of characteristics are given in Figure 9. The cowl shock wave cancellation performs very well at the design Mach number. Below the design Mach number, the internal shock wave moves forward of the cancellation point and subsequent shock and expansion waves can be seen in the other profiles. However, the profiles are still rather flat and uniform over most of the fan face from Mach 1.60 to 3.20 . This particular design shows good flow quality at the fan face over the entire started flight Mach number range.

The average fan face Mach number operation from takeoff to cruise is presented in Figure 10. Below the inlet starting Mach number of 1.60 , the inlet can operate over a range of subsonic flow at the fan face as shown in the series of subsonic operating lines. The started inlet operation is indicated by the single supersonic fan face Mach number curve. since this inlet is fixed geometry, the free stream Mach number uniquely defines the fan face Mach number for this design.

The implications of this mode of supersonic through-flow fan operation are presented in Figures 11-13. The started air flow is fixed by the inlet in Figure 11, while in unstarted operation the inlet can deliver a range of air flows shown by the series of curves for the subsonic fan face Mach numbers from 0.60 to 0.90 . The total pressure recovery schedule in Figure 12 shows a cruise recovery of 0.98 . However the takeoff recoveries fall below 0.90 as a result of sharp lip losses. These values are also without takeoff doors. The inlet preentry spillage drag coefficients are given in Figure 13. The transonic drag rise is sensitive to fan face Mach number for this design also, more than doubling between 0.90 and 0.60 . Again it is proposed that this fixed geometry inlet does not require any boundary layer bleed because of the small overall diffusion and lack of terminal normal shock. The cruise cowl wave drag coefficient for a 5.0 degree external cowl angle is 0.013 at a free stream Mach number of 3.20 . The preentry spillage and cowl wave drag comprise the total inlet aerodynamic drags, neglecting nacelle skin friction.

This fixed geometry primary inlet looks attractive when compared with the variable geometry primary inlet. The fixed geometry inlet has a $2 \%$ higher cruise total pressure recovery, a $49 \%$ higher transonic air flow capability, and a lower transonic preentry spillage drag than the variable geometry primary inlet. The fixed geometry inlet is also $21 \%$ shorter than the variable geometry inlet. However, the fixed geometry inlet has a significantly lower takeoff total pressure recovery. Additionally the impact on the supersonic through-flow fan design enabling subsonic operation must be assessed in correctly comparing the two different operation schemes.

\section{Core Inlet}

Based on estimates of the mean fan exit Mach number over the supersonic through-flow range, the local incoming Mach number for the core inlet (refer to Figure i) was Iimited to between 2.50 and 3.50. This operating range is a function of flight Mach number for a specific primary inlet and fan speed. In addition to matching a core inlet design with fan exit Mach number excursion, it was necessary to pay particular attention to the airflow characteristics in order to produce a design consistent with the engine bypass ratio variations dictated by cycle matching. Initial attempts to produce a short compact geometry invariably lead to difficulties in meeting cycle bypass ratio requirements. This resulted from excessive air capture lapse characteristic of core inlet designs with substantial compressive turning ahead of the core inlet lip. A satisfactory preliminary design was arrived at, after many iterations, which matched the cycle bypass ratio demands as well as providing acceptable total pressure recoveries. The design shown in Figure 14 consists of a gradual isentropic turning ahead of a rather strong core inlet lip compressive turn. The core inlet has a sliding shroud control scheme where the 1 ip is translated fore and aft, adjusting the throat area to accommodate changes in the incoming fan exit Mach number variations. It is also estimated that boundary layer bleed rates varying linearly from $7 \%$ of the capture flow at an incoming Mach number of 2.5 to $10 \%$ at 3.2 will be necessary for the core inlet operation. The core inlet design incorporated a high normal shock Mach number of 1.5 for additional stability margin.

Figure 15 shows the total pressure recovery performance for the core inlet design as a function of normalized fan corrected speed and flight Mach number. The expected normal operation is between recoveries of 0.88 and 0.84 . Figure 16 shows the variation in bypass ratio with flight Mach number and fan speed. The lower asymptote in bypass ratio is the cruise design point, for this particular example 0.50 . Off design the change in bypass ratio can be significant, either by dropping the flight Mach number or the fan corrected speed. Performance of the core inlet with subsonic inflow, as would be 
produced by an unstarted fan, is expected to be similar to a flow splitter performance in a conventional turbofan engine. With subsonic inflow the bypass ratio could be raised substantially. For a designed bypass ratio of 0.5 at Mach 3.20 cruise, a supersonic through-flow fan engine operating in subsonic inflow mode could have a takeoff and subsonic bypass ratio of 1.5 or higher.

\section{Conventional Inlet}

For the purpose of comparison, Figure 17 shows a conventional supersonic inlet design prepared in the same manner as the other two supersonic through-flow fan primary inlets. This inlet is controlled by a translating centerbody scheme and has a cruise boundary layer bleed requirement of $10 \%$. Figures $18-20$ show the performance characteristics of the conventional inlet.

In comparison with the supersonic through-flow fan fixed geometry primary inlet, the conventional inlet has a total pressure recovery of 0.87 at Mach 3.20 cruise, while the former has a recovery of 0.98 . The supersonic through-flow fan and conventional inlets, however, do not diffuse the flow to the same state and therefore this comparison in recoveries should be used cautiously.

The conventional inlet captures $34 \%$ less air flow and has $43 \%$ higher drags at transonic speeds than the supersonic through-flow fan fixed geometry primary inlet. The conventional inlet also has a cruise bleed drag coefficient of 0.063 compared to none for the supersonic through-flow fan primary inlets. The core inlet does require bleed, however, the drags are anticipated to be much smaller than those associated with the conventional inlet. If the bleed flow from the core inlet could be reintroduced into the fan bypass stream, then the core inlet bleed drag could be effectively eliminated.

The supersonic through-flow fan fixed geometry primary inlet is $42 \%$ shorter and weighs only $11 \%$ as much as the conventional inlet. Even with the inclusion of the core inlet weight estimate, the conventional inlet is still 37 \% heavier.

\section{SUMMARY}

A preliminary design study was
undertaken to assess the performance
characteristics of two classes of
supersonic through-flow fan primary inlets
and a core inlet. Analyses by method of
characteristics and one-dimensional
performance indicated
substantial improvement potential in inlet
system performance for supersonic through-
flow technology compared to conventional.

For Mach 3.20 cruise, supersonic throughlow fan primary inlets can have higher total pressure recoveries, lower transonic crags, higher air flow capacity and lighter weights than conventional inlet systems. Further work needs to be continued to perform more realistic iiscous calculations to verify these lreliminary findings. The effects of nlet centerbody support struts need to be ncluded in future work. Additional esearch in the areas of inlet stability, istortion, and control for core inlets hould also be undertaken.

\section{Acknow ledgement}

This research was sponsored by the JASA Lewis Research Center, Cleveland, thio, under contract number NAS3-24105.

\section{REFERENCES}

1. Trucco, H., "Study of variable cycle ingines Equipped with Supersonic Fans, inal Report", ATL TR 201 Advanced rechnology Laboratories Inc., NAS3-17559, NASA CR-134777, 1975.

?. Franciscus, L. C., "Supersonic Through-Elow Fan Engines for Supersonic cruise Aircraft", NASA TM-78889, 1978.

3. Franciscus, L. C., "The Supersonic Through-Flow Turbofan for High Mach Propulsion", NASA TM-100114, AIAA-87-2050, Iuly, 1987.

4. Anderson, B. H., "Design of Supersonic Inlets by a Computer Program Incorporating the Method of Characteristics", NASA TN-D$1960,1969$.

j. Sorensen, V. L., "Computer Program for Calculating Flow Fields in supersonic Inlets", NASA TN-D-2897, 1955.

5. Crosthwait, E. L., Kennon, I. G. Jr., Roland, H. L., et al, "Preliminary Design Methodology for Air-Induction systems". SEG-TR-67-1, General Dynamics, Fort worth Division, $A F 33(615)-3125,1967$.

7. Tindell, R., Delaney, F., et al, "Level II Inlet Installation Program volume I Final Report", AFWAL-TR-833077 Vol I, Grumman Aerospace Corporation, F33615-81-C-3029, 1983 .

3, Ball, W. H., "Propulsion system Installation Corrections volume I: Engineers Manual", AFFDL-TR-72-147, The Boeing Company, F33615-72-C-1580, 1972.

7. Sibulkin, M., "Theoretical and Experimental Investigation of Additive Drag", NACA Report 1187, 1951.

10. Moeckel, W. F., "Approximate Method for Predicting Form and Location of 
Detached Shock Waves Ahead of Plane or Axially symmetric Bodies", NACA TN-1921, 1949.

11. Fradenburgh, E. A. and waytt, D. D., "Theoretical Performance Characteristics of Sharp-Lip Inlets at subsonic speeds", NACA Report 1193, 1953.

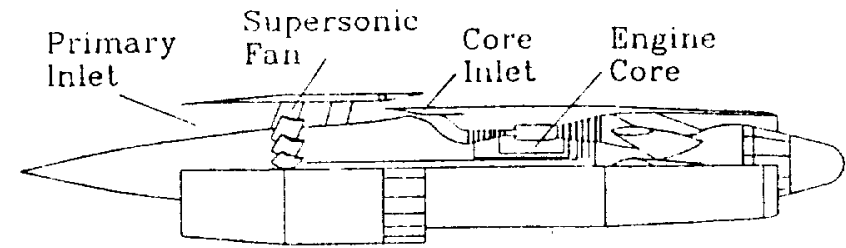

Fiqure 1: Supersonic through-flow fan engine concept.

Design Mach Number 3.20

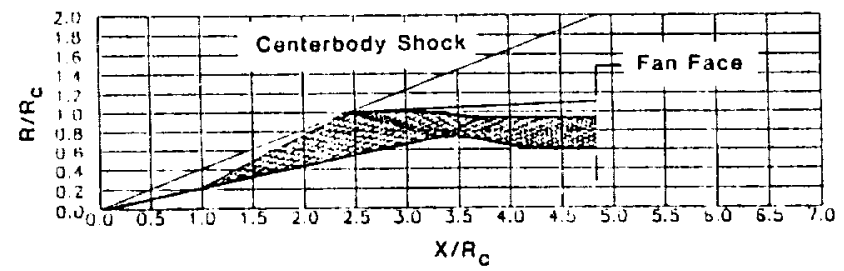

Figure 2: supersonic through-flow fan variable geometry primary inlet.

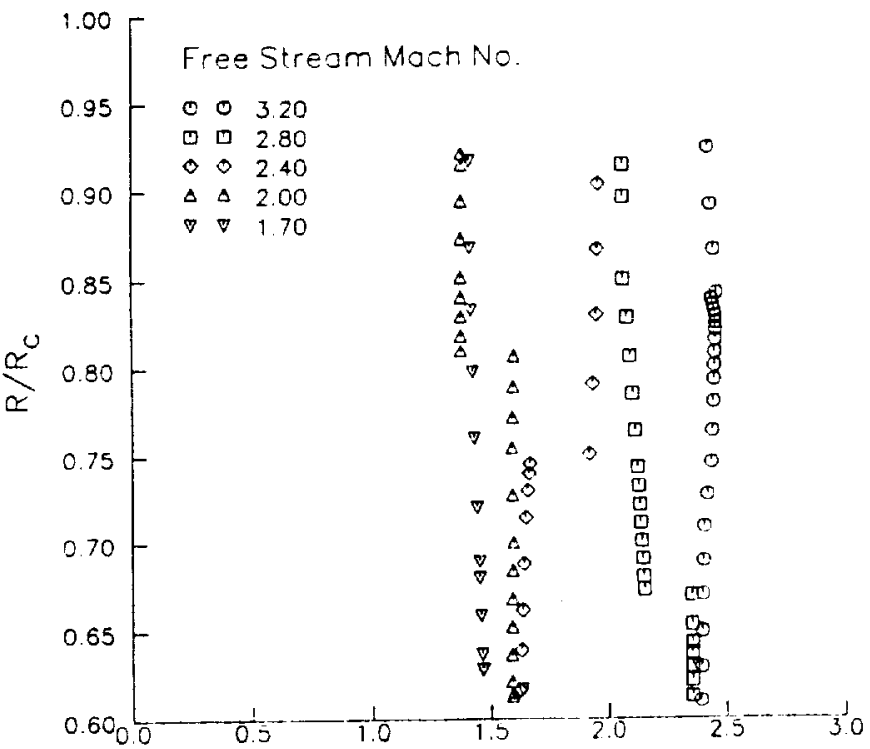

Fan Foce Mach Number

Figure 3: Variable geometry primary inlet fan face Mach number profiles for started operation.

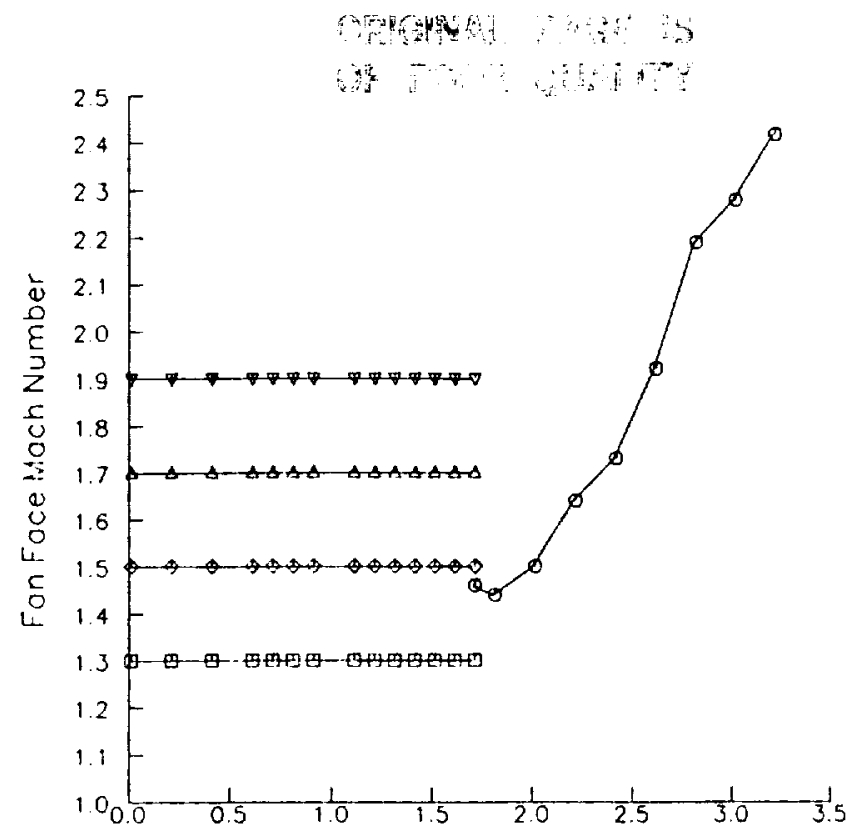

Free Stream Moch Number

Figure 4: Variable geometry primary inlet average fan face $\mathrm{Mach}$ number operation.

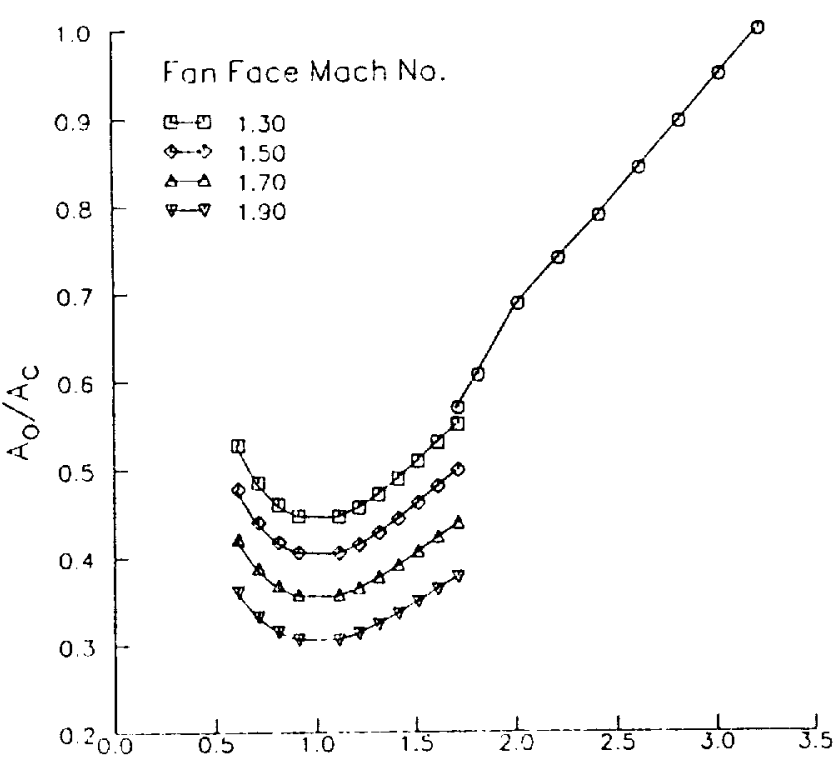

Free Stream Moch Number

Figure 5: Variable geometry primary inlet air flow schedule. 


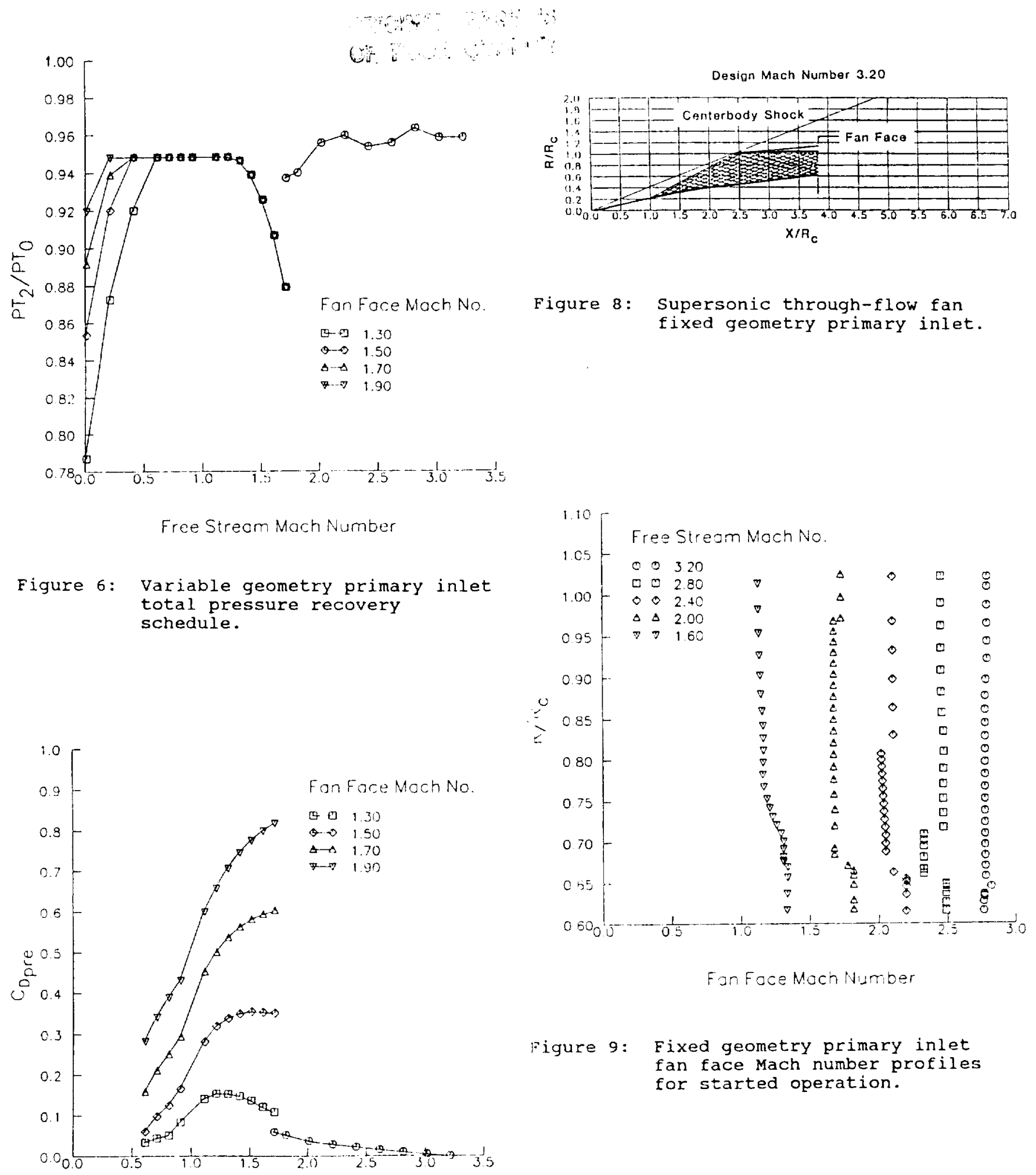

Free Streom Moch Number

Figure 7: Variable geometry primary inlet preentry spillage drag coefficients. 


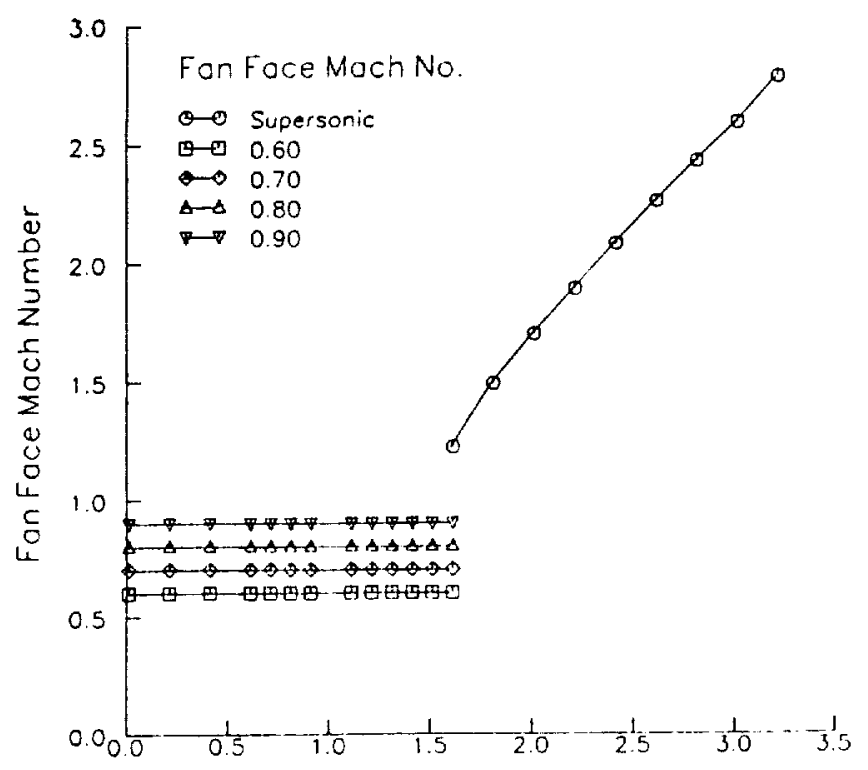

Free Streom Mach Number

Figure 10: Fixed geometry primary inlet average fan face Mach number operation.

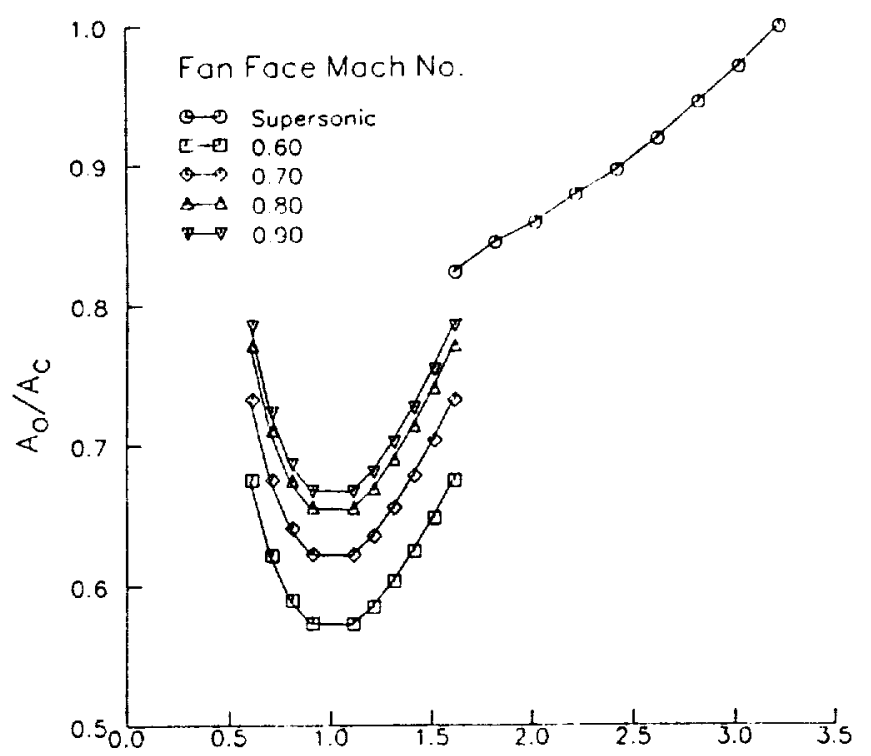

Free Streom Moch Number

Figure 11: Fixed geometry primary inlet air flow schedule.

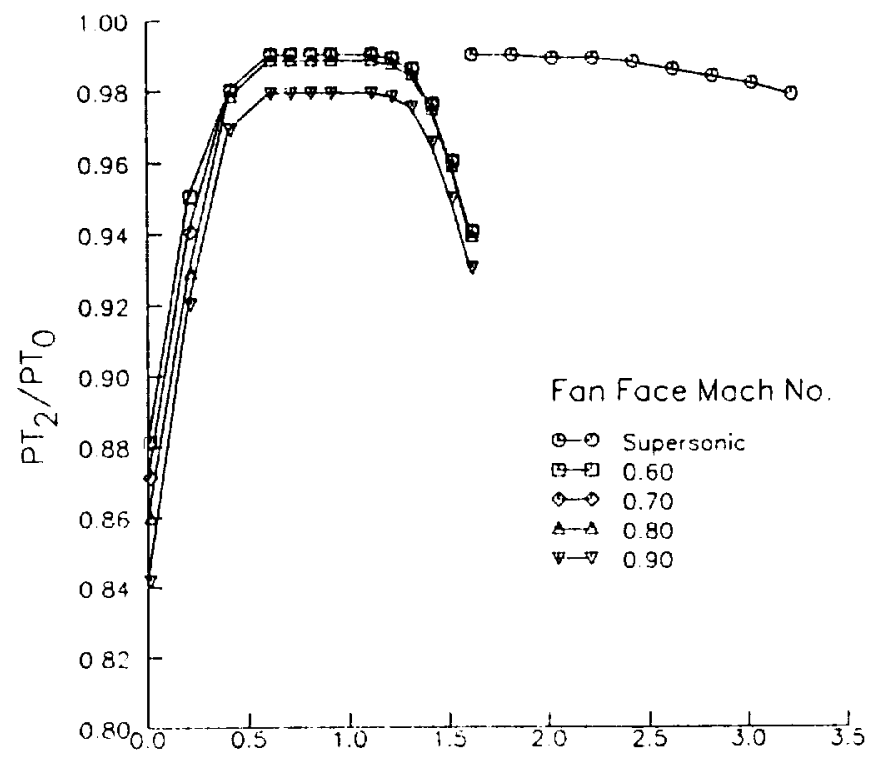

Free Streom Moch Number
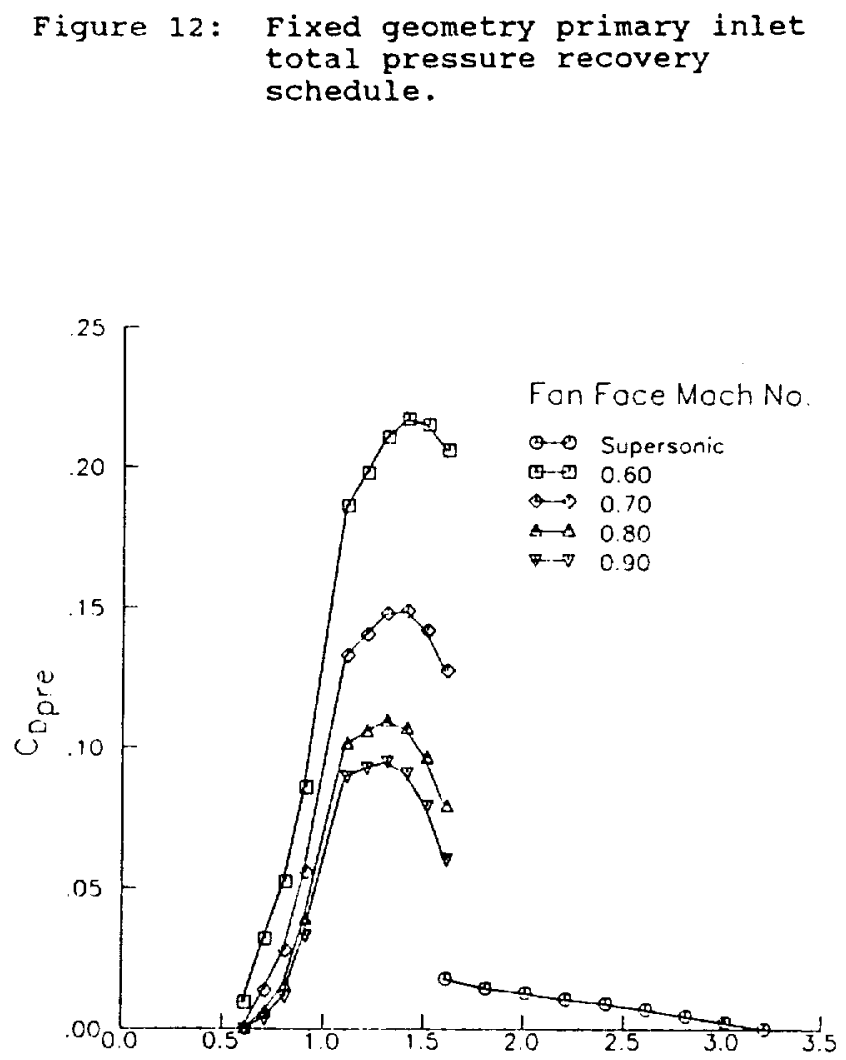

Free Stream Mach Number

Figure 13: Fixed geometry primary inlet preentry spillage drag coefficients. 
ORIGINAL. PAGE IS

OF POOH QUALITY

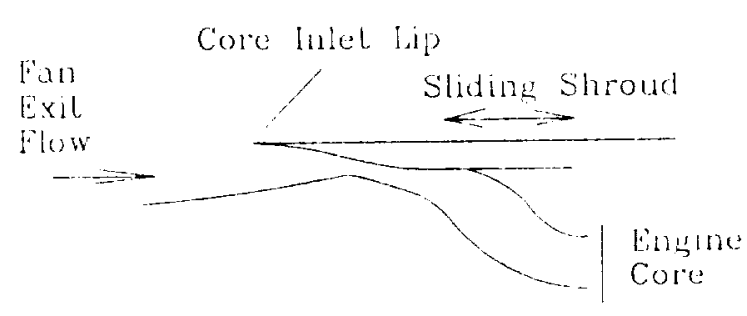

Figure 14: Supersonic through-flow fan core inlet.

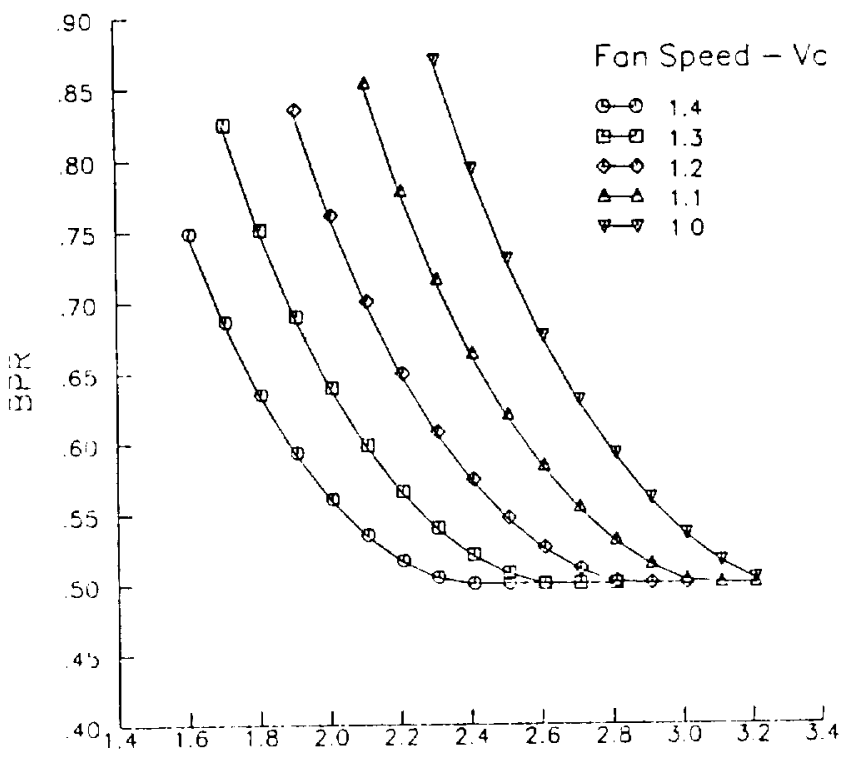

Free Stream Moch Number

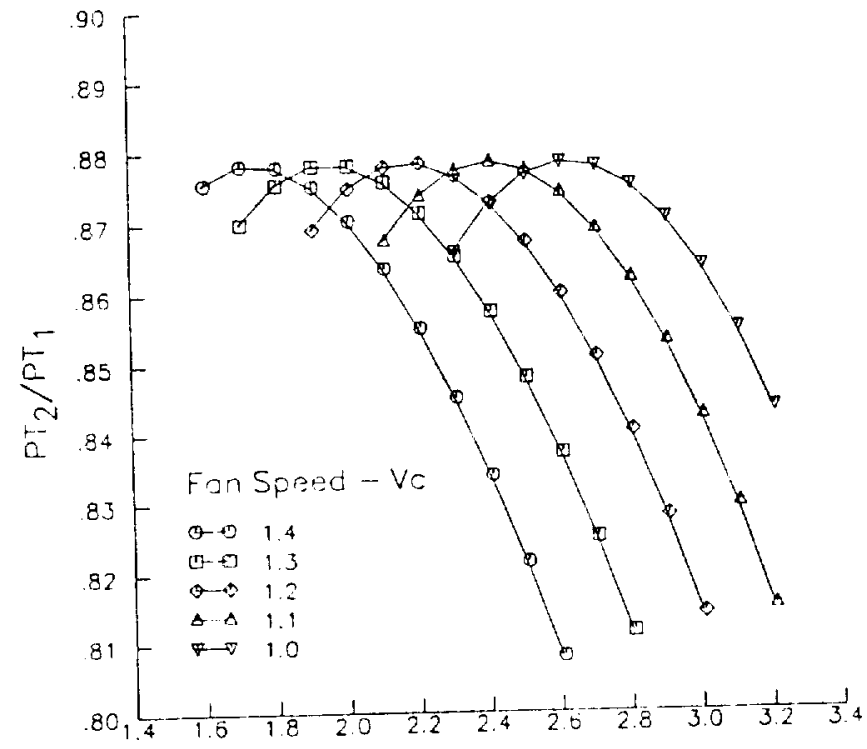

Figure 16: Core inlet bypass ratio schedule.

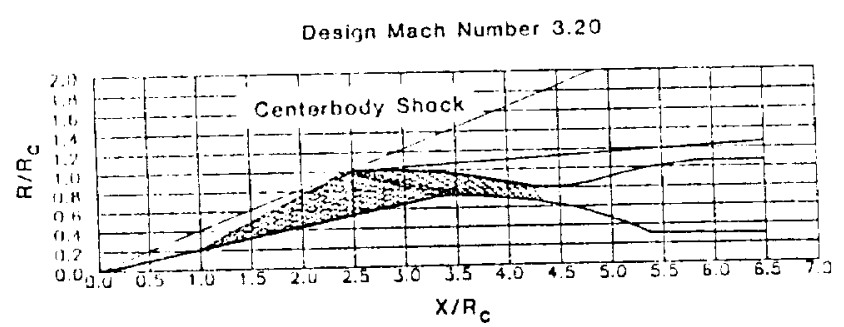

Free Stream Moch Number

Figure 15: Core inlet total pressure

Figure 17: Conventional translating recovery schedule. 


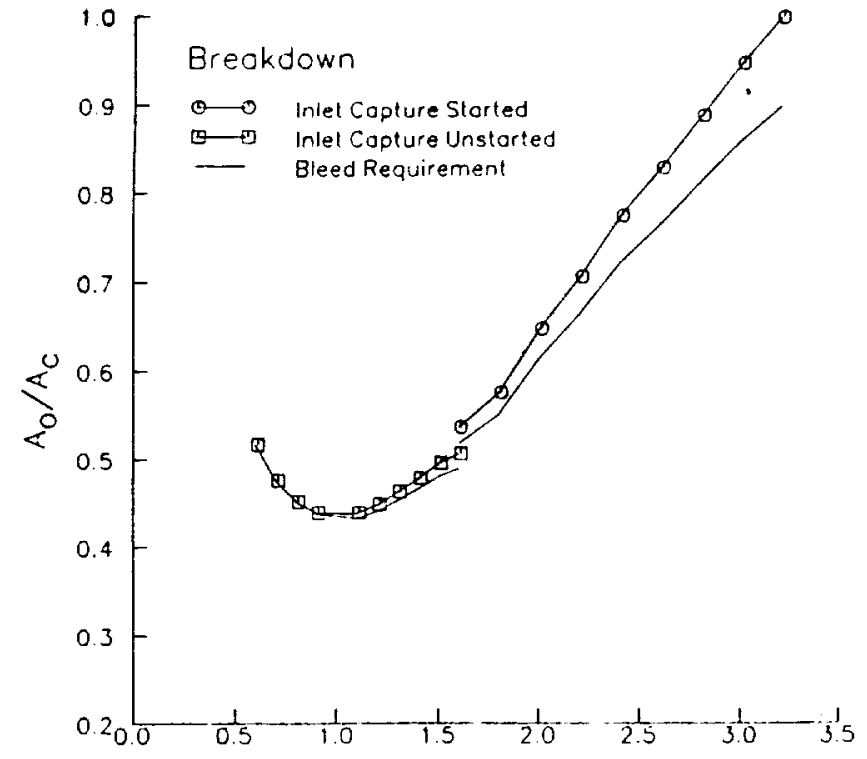

Free Stream Mach Number

Figure 18: Conventional inlet air flow schedule.

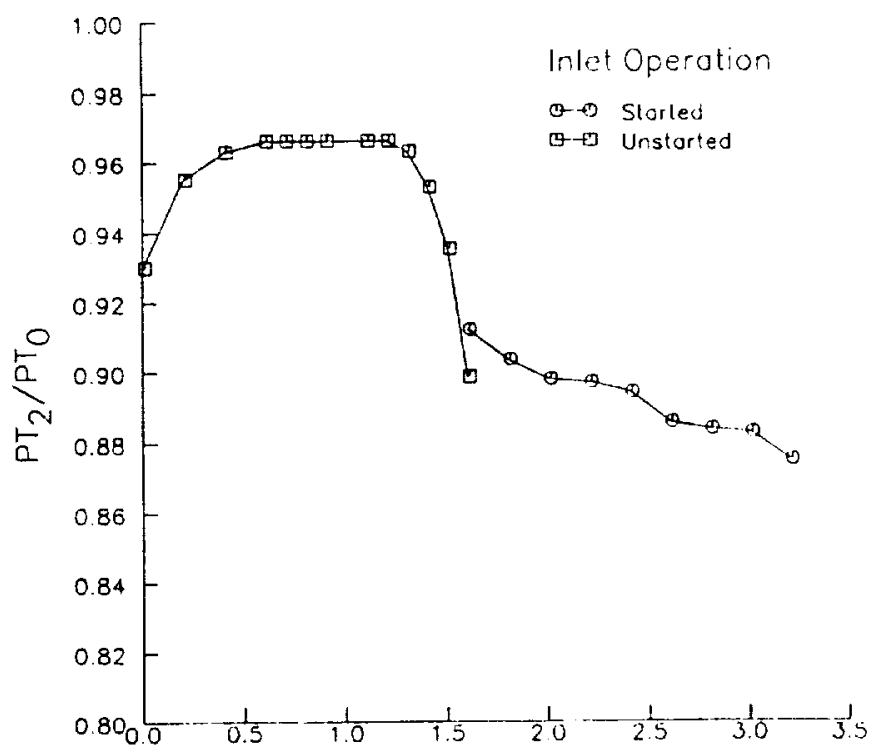

Free Stream Moch Number

Figure 19: Conventional inlet total pressure recovery schedule.

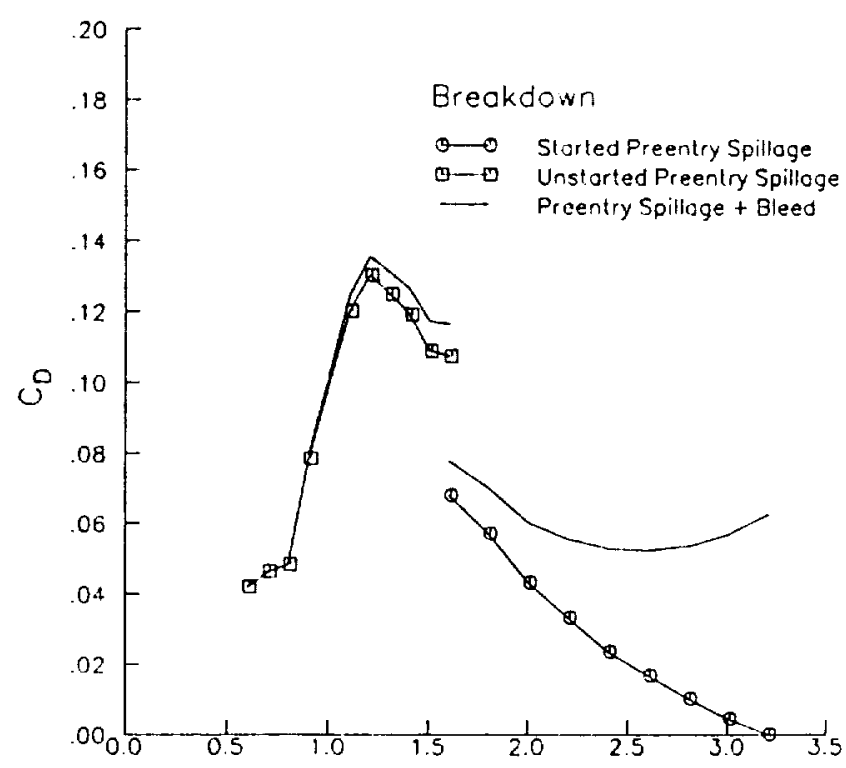

Free Streorn Mach Number

Figure 20: Conventional inlet drag coefficients.

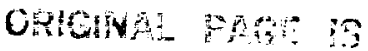

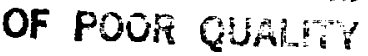




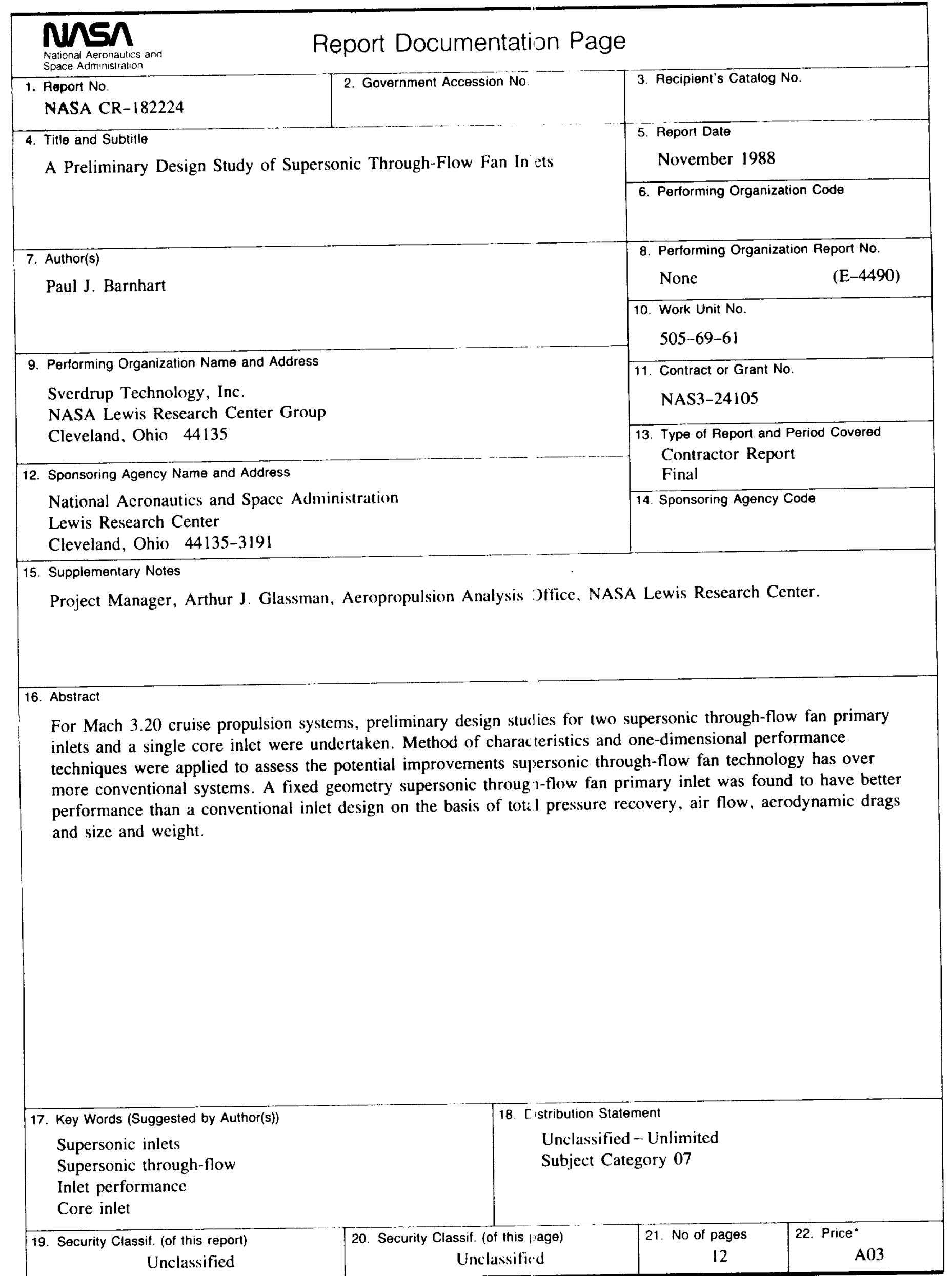


